\title{
Municipal Police Officer Fatally Injured When Struck by a Backing Dump Truck - Massachusetts
}

Release Date: June 18, 2014

Investigation: \# 12-MA-016-01
Massachusetts Department of Public Health Occupational Health Surveillance Program

\section{SUMMARY}

On July 26, 2012, a 53-year-old male municipal police officer (victim) was fatally injured when he was struck by a backing dump truck while performing a traffic detail for a water line replacement project. The victim was directing traffic when he noticed a backing dump truck. As he tried to get out of the truck's way, he fell and the truck backed onto him. The truck operator exited the truck's cab and noticed that the truck was on top of the victim, he then moved the truck off of the victim. Emergency medical services (EMS) arrived within minutes of notification and transported the victim to a local hospital where he died later that same day.

Contributing factors identified in this investigation included: the contractor lacked an Internal Traffic Control Plan and backing procedures, and the dump truck was not equipped with monitoring technologies to assist the truck operator monitor vehicle blind spots. In addition, the police department did not provide work zone training for police officers performing details for construction projects.

The Massachusetts FACE Program concluded that to prevent similar occurrences in the future, contractors performing work on or around roadways should:

- Develop, implement, and enforce an Internal Traffic Control Plan (ITCP) specific to each construction site to minimize vehicle backing and to help protect workers on foot;

- Ensure backing protocols are in place and that designated individuals are assigned as signalers to direct backing vehicles on construction sites; and

- Consider installing monitoring technology on construction vehicles and equipment to assist operators in detecting workers on foot within blind areas.

Municipalities should:

- Provide work zone safety training for all employees who perform work on or around roadways, including traffic details; and

- Provide work environments for employees that, at a minimum, meet all relevant Occupational Safety and Health Administration (OSHA) regulations and industry accepted standards of practice per the Department of Labor Standards policy.

Manufacturers of heavy construction equipment and vehicles, such as dump trucks, should:

- Explore the possibility of incorporating collision avoidance technology on their equipment to assist the operator while backing. 


\section{INTRODUCTION}

On July 26, 2012, the Massachusetts FACE Program was alerted by the local media that earlier that same day a male municipal police officer had died from injuries sustained when he was struck by a backing dump truck. An investigation was initiated and on October 18, 2012, representatives from the Massachusetts FACE Program and the Massachusetts Department of Labor Standards (DLS) traveled to the municipal police department and met with a police department representative to discuss the incident. The police report and death certificate were reviewed during the course of the investigation. Photographs were taken of the incident location.

\section{EMPLOYER}

The victim's employer was a municipal police department for a Massachusetts city with more than 41,000 residents. The city was undergoing a large water line replacement project at the time of the incident. The city's police officers have union representation.

\section{WRITTEN SAFETY PROGRAMS AND TRAINING}

The police department did not have written safety and health procedures specific to traffic details and work zones. The police academy training curriculum for recruits typically includes a brief session on traffic details/work zone safety. This is usually one of the only times that officers receive training on this topic. Because the victim had received his initial police training prior to the inclusion of the work zone safety training at the academy, he had not been through work zone safety training.

\section{VICTIM}

The victim was a 53-year-old male municipal police officer who had been employed by the city's police department for approximately 27 years. The victim was wearing an American National Standard Institute (ANSI) Class II vest on the day of the incident.

\section{INCIDENT LOCATION}

The incident occurred on a rural residential roadway within a municipality incorporated as a city. The roadway was comprised of asphalt and had two lanes; a single northbound lane and a single southbound lane (Figure 1). The speed limit for the roadway was an un-posted 30 miles per hour (MPH) residential area. The roadway's markings consist of double center yellow lines separating the single northbound and southbound travel lanes. There were no painted white fog lines along the roadway edges. The width of each lane varied from 12 feet to 15 feet depending on the location along the roadway.

At the incident location, the roadway's shoulders were a mix of dirt and vegetation. The shoulder at the eastern edge of the northbound lane had a slight incline and the shoulder at the western edge of the southbound lane was relatively flat. Residential houses were located on both sides of the roadway at the incident location. The residence at the eastern side of the roadway was located closer to the roadway edge than the residence at the western side of the roadway. Land located on the western side of the roadway was being used as a staging area for the water 
line replacement project. At the northern end of the incident location, the roadway curved to the east and declined while heading north (Figure 2).

On the day of the incident both the northbound and southbound roadway traffic had been limited to using the southbound lane only directed by police personnel. The roadway was in poor condition due to the water line replacement project. At the time of the incident, the center of the roadway, which had been previously excavated, was filled with gravel and the roadway was wet due to light rain.

\section{VEHICLE}

The vehicle involved in the incident owned by the contractor was a yellow dump truck manufactured in 1979. The truck was powered by an eight cylinder diesel engine, had a manual transmission and was rear wheel drive. The truck had three rear axles all with dual wheels. The vehicle was equipped with a backup alarm that was functional and operating at the time of the incident.

State police personnel inspected the vehicle after the incident, and reported that the vehicle was not damaged during the incident and that the backing system was operating normally. It was also reported that the vehicle's lights and windshield wipers were off and that the radio was on with the volume set at a moderate level at the time of the incident. The state police also noted that while seated in the truck's cab a blind spot obstructs the ability to view a large area around the rear of the truck.

\section{INVESTIGATION}

The incident occurred at approximately 7:25 a.m. and although it was daylight at the time of the incident there were overcast skies. The temperature was 68 degrees Fahrenheit with intermittent light rain and light winds. There were five officers/police personnel performing traffic details at the work site the morning of the incident. The victim's assigned location was in the middle of the work zone to help direct the two-way traffic use the single travel lane that was open.

The dump truck involved in the incident was parked in the construction project staging area prior to the incident. The dump truck drove out of the staging area in the forward direction and one of the officers performing a traffic detail was directing the truck. As the dump truck exited the staging area it pulled into the closed northbound travel lane facing south and then stopped. At this point the victim was standing behind and had his back to the dump truck concentrating on directing the oncoming traffic traveling in the southbound travel lane (Figure 2).

Immediately before the incident, the victim stopped a vehicle traveling in the southbound travel lane. The operator of this stopped vehicle noticed that the victim was standing directly behind the dump truck located in the northbound travel lane with his back to the truck as the truck started to back towards the north. At the same time, a front end loader owned by the contractor was also located in the northbound travel lane and was backing in a southerly direction and dragging a large steel plate, which had been used to cover an excavated section of the roadway. 
The backing front end loader was equipped with a functional backup alarm that was working at the time of the incident.

When the operator of the stopped vehicle noticed that the victim was going to be struck by the backing dump truck, the operator started to beep the vehicle's horn. The victim then became aware of the backing dump truck and headed east to the roadway's shoulder in an attempt to get away from the truck. It appears as the victim stepped onto the incline of the roadway's shoulder that he slipped or lost his footing and fell onto the roadway.

The operator of the backing dump truck heard the car horn and stopped the truck. The truck operator then exited the truck's cab and noticed that the truck's third axle rear dual wheels were on top of the victim. The truck operator then immediately got back into the cab and moved the truck forward approximately 10 feet off of the victim.

Co-workers went to assist the victim and a call was placed for emergency medical services (EMS). EMS and state police arrived within minutes. The victim was transported by ambulance to a local hospital. The victim died later that same day.

\section{CONTRIBUTING FACTORS}

Occupational injuries and fatalities are often the result of one or more contributing factors or key events in a larger sequence of events that ultimately result in the injury or fatality. The Massachusetts FACE team identified the following contributing factors in this incident.

Contractor performing the water line replacement:

- Lack of an Internal Traffic Control Plan (ITCP).

- No backing procedures.

- Dump truck not equipped with monitoring technologies to assist the truck operator monitor vehicle blind spots.

Police department:

- Work zone training not provided to officers performing construction projects details.

\section{CAUSE OF DEATH}

The medical examiner listed the cause of death as multiple injuries involving right and left pelvis and both thighs due to blunt force trauma. 


\section{RECOMMENDATIONS/DISCUSSION}

\section{Recommendation \#1: Contractors performing work on or around roadways should develop, implement, and enforce an Internal Traffic Control Plan (ITCP) specific to each construction site to minimize vehicle backing and to help protect workers on foot.}

Discussion: In work environments where mobile equipment are being operated, workers on foot are exposed to potential struck-by hazards, particularly being backed over. ${ }^{1}$ An Internal Traffic Control Plan (ITCP) is a tool that a project manager can use to coordinate the flow of construction vehicles, equipment, and workers on foot moving in close proximity to each other on a construction site., ${ }^{2,3}$ An ITCP should be developed for all medium, large, and multicontractor jobs, such as this water line replacement job. The ITCP should be included as part of the company's comprehensive health and safety program.

To reduce the hazard associated with backing construction vehicles and equipment, an ITCP can be developed to minimize the backing distances of all vehicles and equipment on a work site with the goal of eliminating backing vehicles and equipment altogether. This can be accomplished by taking into consideration the tasks to be performed by the vehicles and equipment and how the vehicles and equipment can safely navigate through the construction site to complete these tasks while backing as little as possible. The ITCP should also address workers on foot by creating walking zones for these workers that are clear of backing construction vehicles and equipment. ${ }^{3}$ This can be accomplished by taking into consideration the tasks to be performed by the workers on foot, and how these workers can safely navigate through the construction site to complete these tasks. Some areas within a construction work zone might have to be defined as areas that are prohibited for workers on foot. Providing employees training on the ITCP and sharing the plan with all workers on the site, including any sub-contractors and police departments providing traffic details, is essential for the ITCP to be effective.

\section{Recommendation \#2: Contractors performing work on or around roadways should ensure backing protocols are in place and that designated individuals are assigned as signalers to direct backing vehicles on construction sites.}

Discussion: In this case, if backing protocols had been established and there was a person assigned as a backing signaler, the dump truck would not have been able to start backing until the signaler was sure it was safe to start. Backing protocols should be developed and implemented for each construction project where there will be backing vehicles and workers on foot. The employer should provide employees training on the backing protocols. These protocols should include, but not be limited to, an assigned backing signaler ${ }^{4}$ and policies that backing will not begin without an understandable signal from the signaler that it is safe to start backing. The established protocols should also state that operators of construction vehicles and equipment must come to a complete stop if contact with the signaler is lost and they must not resume backing until contact is re-established. All equipment operators and truck drivers, upon entering the construction site, should be notified of who the signalers are and about the backing protocols, which at this same time the backing protocols should be reviewed. 
Backing protocols could also include Blind Area Diagrams for construction vehicles and equipment. NIOSH has information available on blind areas around construction vehicles and equipment primarily for safety personnel and instructors to be used as training aides in developing awareness about hazardous areas around construction vehicles and equipment due to limited visibility. Blind Area Diagrams and test procedures (information on how to develop your own diagrams) are available on the NIOSH Web site at www.cdc.gov/niosh/topics/highwayworkzones/BAD/imagelookup.html. ${ }^{5}$

In addition, signalers could be equipped with an air horn that would only be used when a hazard exists from backing vehicles. Air horns might get the attention of backing vehicle operators, the operators of other equipment, or workers on foot, potentially reducing the hazard of backing vehicles striking workers on foot. Of course this is only an aide to help maintain constant communication/sight between backing drivers and their signalers.

\section{Recommendation \#3: Contractors performing work on or around roadways should consider installing monitoring technology on construction vehicles and equipment to assist operators in detecting workers on foot within blind areas.}

Discussion: Aftermarket monitoring technology, such as sensor based systems, rear-view cameras, and radio frequency identification (RFID) tags and tag readers, are available to assist in monitoring vehicle blind spots. ${ }^{1}$ These systems could give operators a better view and sense of what is located in blind spots, especially when backing.

Combining the use of monitoring systems, such as a rear-view camera and a sensor system, which provides an alarm in the cab when a person or object is detected at the rear of the vehicle, along with some administrative controls, such as an ITCP, backing procedures, and a buddy system, will help minimize the possibility of a worker on foot being backed over.

\section{Recommendation \#4: Municipalities should provide work zone safety training for all employees who perform work on or around roadways, including traffic details.}

Discussion: Training municipal workers in work zone safety, including work zone setup and design, would provide workers and officers knowledge to better protect, not only themselves, but also construction workers, pedestrians, and motorists. The possibility of extending training to include other hazards common on roadway construction sites, such as trenching and backing vehicles and equipment, should also be considered.

In Massachusetts, the State Police train troopers in work zone safety during their academy training. This existing training course, based on the Manual on Uniform Traffic Control Devices (MUTCD), Part 6, which governs work zone designs, could be used as an outline to develop training for local city and town officers. ${ }^{6}$ 


\section{Recommendation \#5: Municipalities should provide work environments for employees that, at a minimum, meet all relevant Occupational Safety and Health Administration (OSHA) regulations and industry accepted standards of practice per the Department of Labor Standards policy.}

Discussion: The federal Occupational Safety and Health Act require private sector employers to provide workplaces that are free from recognized hazards likely to cause death or serious physical harm to employees. While private sector employees are covered by federal OSHA, public sector employees in Massachusetts are not. The Massachusetts Department of Labor Standards (DLS), in accordance with Chapter 149 Section 6, is charged with inspecting public sector workplaces in Massachusetts and determining what procedures and practices are required to protect workers. ${ }^{7}$ As a matter of policy, DLS references OSHA Standards, standards set forth in the MUTCD, as well as other consensus standards such as those developed by the American National Standards Institute (ANSI), in determining whether proper procedures are being followed to protect workers. Municipalities should ensure that their employees who are performing traffic details are being provided work zone safety training as discussed above in recommendation \#4.

DLS has enhanced efforts to improve health and safety conditions for municipal workers by increasing incident inspections and voluntary technical assistance for municipalities. During an incident inspection if conditions are observed that could cause worker injury or illness, a written warning will be issued by DLS with an order to correct the identified hazards. If the identified hazards are not corrected within the timeframe specified in the written warning, then monetary civil penalties per condition may be issued by DLS to the employer.

\section{Recommendation \#6: Manufacturers of heavy construction equipment and vehicles, such as dump trucks, should explore the possibility of incorporating collision avoidance technology to assist the operator while backing.}

Discussion: In this case and many other cases, the police reported that the truck operator stated he did not see the victim behind the truck. Equipment designed to assist operators in detecting workers on foot who are within a vehicle's blind spot are available. These equipment include, rear-view cameras, fiber optic systems and radio frequency identification (RFID) tags and tag readers. ${ }^{1,8,9}$

A component of the rear-view camera and fiber optic systems would be mounted at the rear of the equipment, or at a blind spot, and a monitor would be placed inside the operator's area giving the operator an unobstructed view of the area around the rear of the vehicle. The RFID system has each worker on foot wearing a small RFID tag and a tag reader mounted in the equipment. When a tag is sensed within the tag reader's sensing range, the equipment operator receives a warning. 


\section{REFERENCES}

1. NIOSH 2014. Workplace Solutions: Preventing Worker Injuries and Deaths from Backing Construction Vehicles and Equipment at Roadway Construction Worksites. [cited on 2014 June 6]. Available from: URL: http://www.cdc.gov/niosh/docs/wp-solutions/2014-125/pdfs/2014125.pdf.

2. NIOSH 2009. Workplace Safety and Health Topics: Highway Work Zone Safety. [cited on 2013 October 11]. Available from: URL: http://www.cdc.gov/niosh/topics/highwayworkzones/.

3. NIOSH 2001. Building Safer Highway Work Zones: Measures to Prevent Worker Injuries from Vehicles and Equipment, Department of Health and Human Services, Center for Disease Control and Prevention, National Institute for Occupational Safety and Health, DHHS (NIOSH) Publication No. 2001-128.

4. Code of Federal Regulations, 29 CFR 1926.601 (b)(4) Safety and Health Regulations for Construction, Motor vehicles, Government Printing Office.

5. NIOSH 2009. Workplace Safety and Health Topics: Highway Work Zone Safety: Construction Equipment Visibility. [cited on 2013 October 11]. Available from: URL: http://www.cdc.gov/niosh/topics/highwayworkzones/BAD/imagelookup.html.

6. US DOT 2009. Manual on Uniform Traffic Control Devices (MUTCD), 2009 Edition, U.S. Department of Transportation Federal Highway Administration. [cited on 2013 October 11]. Available from: URL: http://mutcd.fhwa.dot.gov/pdfs/2009/part7.pdf.

7. Massachusetts General Laws, Chapter 149: Section 6. Safety devices and means to prevent accidents and diseases generally; fees for structural painting.

8. NIOSH 1998. Program for mining research, navigation and warning aides for mobile equipment, U.S. Department of Health and Human Services, Public Health Services, Centers for Disease Control and Prevention, National Institute for Occupational Safety and Health, DHHS (NIOSH) Publication No. 98-114.

9. NIOSH website: www.cdc.gov/niosh/mining/works/coversheet296.html. NIOSH 2000. Test results of collision warning systems for surface mining dump trucks. U.S. Department of Health and Human Services, Public Health Services, Centers for Disease Control and Prevention, National Institute for Occupational Safety and Health, DHHS (NIOSH) RI 9652. 
12MA016

Page 9

\section{Figure 1 - Incident location looking north}

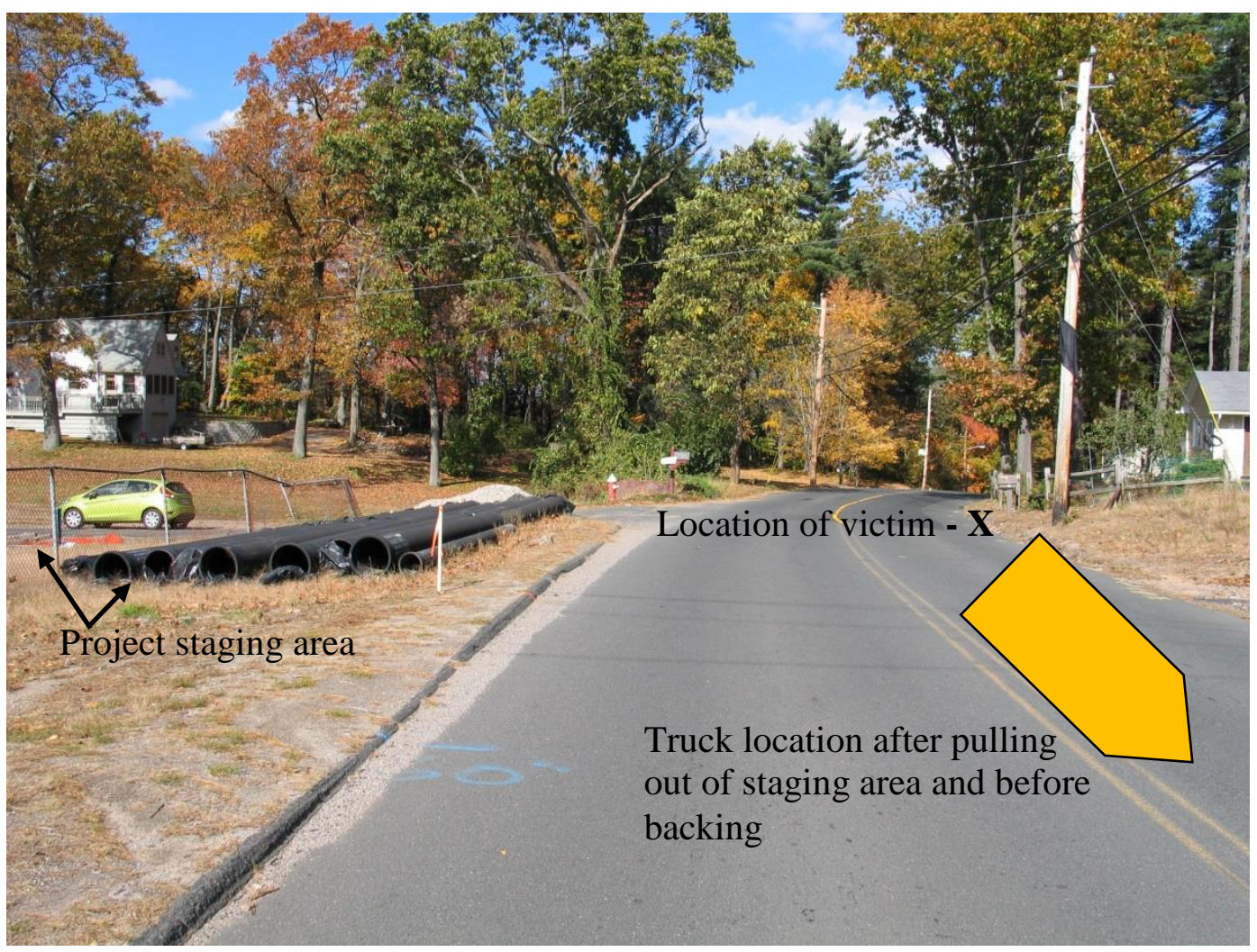


12MA016

Page 10

Figure 2 - Aerial view of the incident location

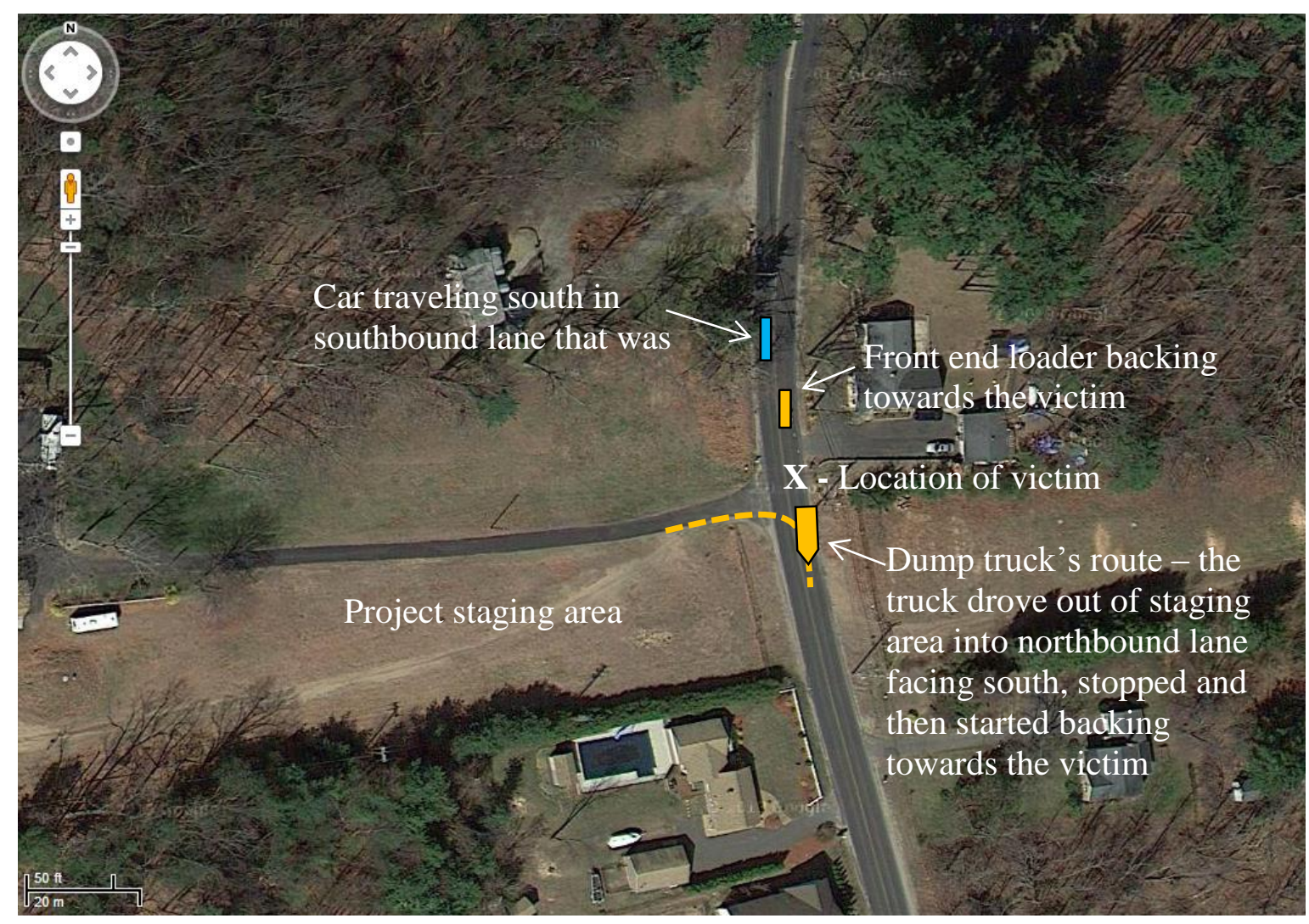

